\title{
Monitoring of Bridge Dynamics by Radar Interferometry
}

\author{
Imrich Lipták, Ján Erdélyi, Peter Kyrinovič, Alojz Kopáčik \\ Slovak University of Technology, Faculty of Civil Engineering, Radlinského 11, 81368 \\ Bratislava, Slovakia, E-mail: imrich.liptak@stuba.sk
}

\begin{abstract}
The paper presents the possibilities of radar interferometry in dynamic deformation monitoring of bridge structures. The technology is increasingly used for this purpose thanks to high accuracy of realized measurements and possibility to measure deformation at multiple places of the monitored structure. High frequency of realized measurements (up to $200 \mathrm{~Hz}$ ) enables to determine the most of significant vibration modes of bridge deformation. This technology is presented on real case study of the cycle bridge over the river Morava near to Bratislava (Slovak republic). A spectral analysis of vibration frequencies is performed by discrete Fourier transformation. The evaluation of correctness of the obtained deformation is performed by comparison of the results with accelerometer and total station measurements and FEM (Finite Element Method) model of the structure.
\end{abstract}

Key words: bridge, dynamic deformation, spectral analysis, ground-based radar

\section{Introduction}

Bridge structures are usually exposed to the greatest extent by external influences such as weather conditions and loading by some objects. These factors have a significant influence on the behavior of the structure, which results in deformation of the whole structure or its parts. Changes in a structure's deformations typically have a cyclical behavior, which reflect the influences of the surroundings. Therefore, the rate of the structure's stress and the magnitude of the impact of individual factors on the structure can be determined.

This paper describes the methodology for processing the data of measurements by ground-based radar. It describes determining the relative displacement approach from a ground-based radar and the possibilities of determining the modal characteristics of any structural deformations. These possibilities are presented in a case study using a mathematical model and a case study involving pedestrian and cycling bridge measurements.

\section{The Technology of Radar Interferometry}

Ground-based radar is an innovative measurement approach for the dynamic deformation monitoring of large structures such as bridges [2], [4] and [6]. Radar measurements use the Stepped Frequency Continuous Wave (SF-CW) technique. This approach enables the detection of target displacements in a radar's line of sight. The basic principle of the technique is the transmission of a set of sweeps, which consist of a number of electromagnetic waves at different frequencies. A pulse radar generates short-term duration pulses to obtain a range resolution, which is related to the pulse durations according to

$$
\Delta r=\frac{c \tau}{2},
$$

where $\mathrm{c}$ is the speed of light in a free space, and $\tau$ is the time of the pulse's flight. At each time interval of the measurements, the components of the received signals represent a frequency 
response measured at the number of discrete frequencies. The application of an Inverse Fourier Transformation (IFT) frequency response is transformed to a time domain. The system then builds a one-dimensional image - a range profile, where the reflectors are resolved with a range resolution according to their distance from the radar (Figure 1 left).

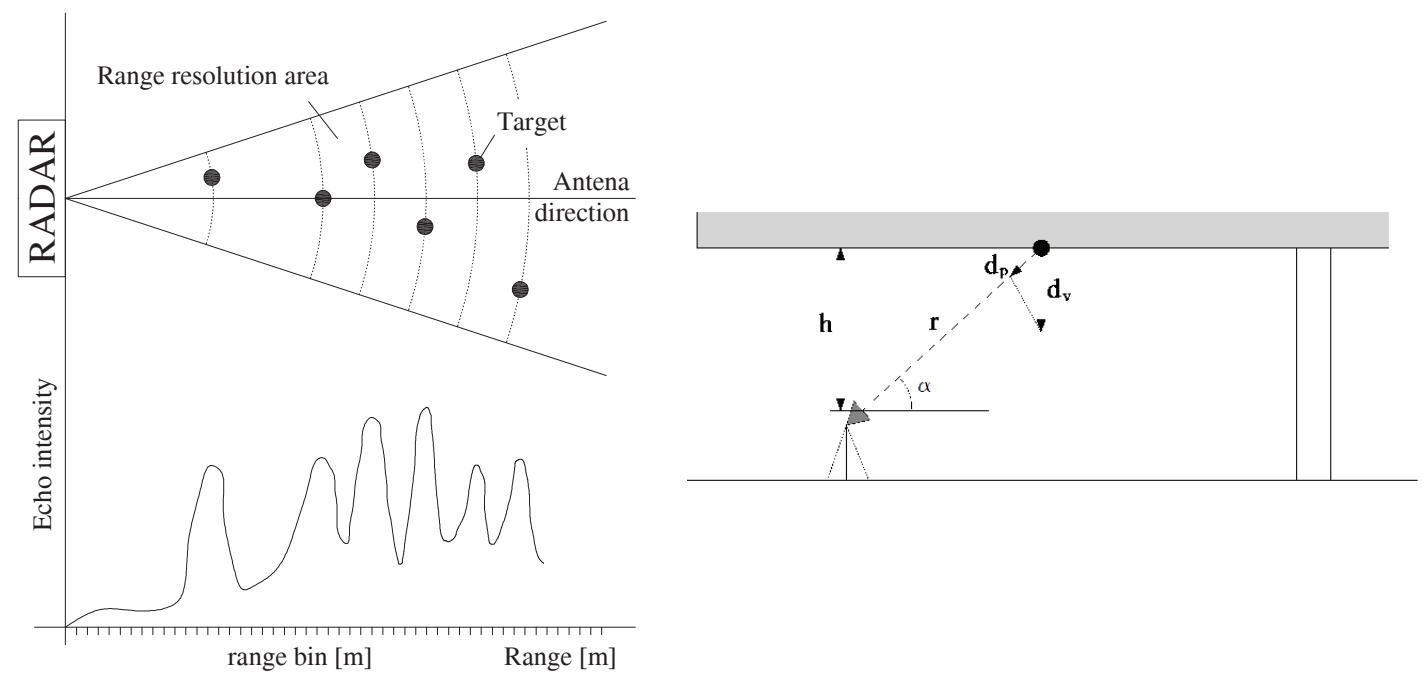

Figure 1: Radar range resolution principle (left) and radial displacement and projected displacement (right)

When the range profile is generated, the displacements of the targets are detected by the Differential Interferometry technique. This approach compares the phase delay of the emitted and reflected microwaves. Radial displacement is therefore linked with the phase delay $\Delta \varphi$ by the following

$$
d_{p}=\frac{\lambda}{4 \pi} \Delta \varphi,
$$

where $\lambda$ is the wavelength of the signal. Radial displacements of the targets can be transformed into vertical displacements according to Figure 1 (right).

\section{Case Study}

The practical use of the ground-based radar, and spectral methods of data processing described in the previous chapter were realized on an actual bridge structure. Bridge structures for pedestrians are usually designed as flexible structures with higher values of deformation amplitudes than road and railway bridges. Experimental measurements were realized on a pedestrian and cycling bridge over the river Morava from Devínska Nová Ves (Slovakia) to Schlosshof (Austria) ([1]). The known modal characteristics of the structure's dynamic deformations are useful for verification of the measured deformations.

Cycling bridge is constructed on a cycling route between an urban area of Bratislava - Devínska Nová Ves - and the Austrian village of Schlosshof (Figure 3). The bridge is a steel truss structure consisting of three parts with a full length of $525.0 \mathrm{~m}$. The main steel structure, which is the subject of the dynamic deformation monitoring, is a symmetrical cable-stayed steel structure (by loading rods, which are anchored at the tops of four steel pylons) with three sections of lengths of $30.00+120.0+30.0=180.0 \mathrm{~m}([1])$. 

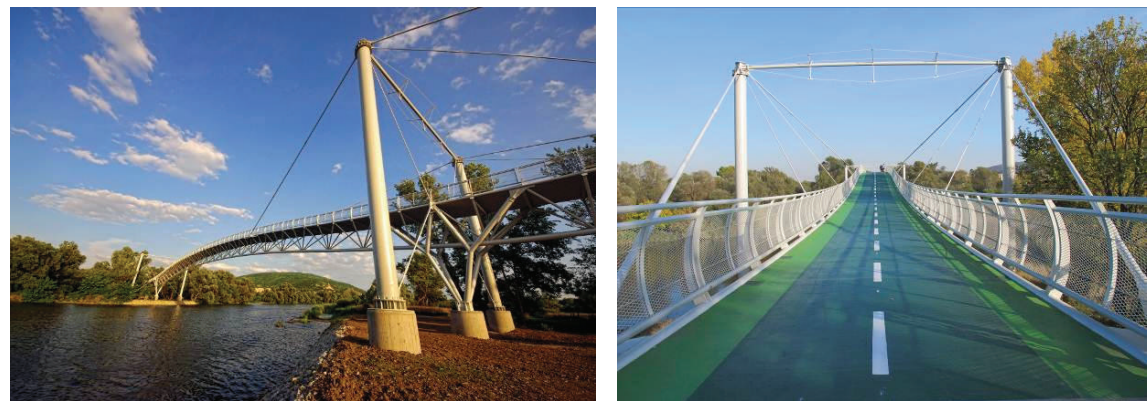

Figure 2: Cycling-bridge in Devínska Nová Ves

\subsection{Dynamic Deformation Measurements}

Higher wind intensity in the surrounding of the bridge, as well as pedestrian movements, have a significant influence on any structural deformations. These deformations are characterized by the vertical bending and horizontal torsional oscillation of the bridge deck.

A ground-based radar IDS IBIS-S measures dynamic displacements by comparing the phase shifts of reflected radar waves collected at the same time intervals. Displacement is measured in a radial direction (line of sight). The minimal radial range resolution of the radar is $0.5 \mathrm{~m}$. The accuracy of the measured displacements is at a level of $0.01 \mathrm{~mm}$, but it depends on the range and quality of the reflected signal [2]. The measurements and data registration are managed by the IBIS-S operational software installed in a notebook.

The measurements were realized during different types of loading of the structure - walking, running and jumping of one person ( $80 \mathrm{~kg}$ weight $)$ at the structure. The types of loading used were designed based on the FEM (Finite Element Method) model of the structure ([3]). The frequency of the data registration by the ground-based radar was realized on the level of $100 \mathrm{~Hz}$ due to the requirements to achieve a higher accuracy of the relative displacements and the occurrence of significant frequencies of structural deformations, which were higher than $10 \mathrm{~Hz}$. The verification of the measured deformation was performed by accelerometer HBM B12/200 and total station Leica TS30 ([5]).
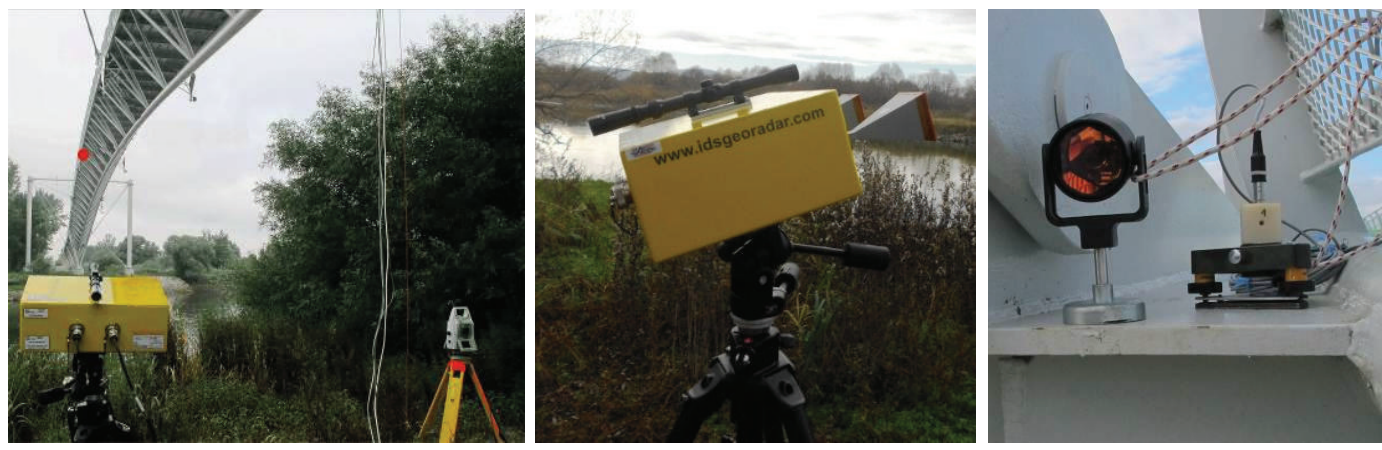

Figure 3: Components of the measurement system

\subsection{Data Processing and Analysis}

Raw displacement data are measured in a radial direction (direction in the line of sight). For our purposes we needed to obtain vertical deformations. The first step in the data processing of the radar measurements is therefore setting the geometry of the structure and defining the position of the radar and measuring points. We can define measured points manually using corner reflectors 
or by finding parts on the structure which have acceptable reflection parameters. In our case the second option was chosen. A good reflection of the signal from the structure defines the range bin profile (Figure 4). The selected peak corresponds to the position of the accelerometer and the prism stabilized on the centre of the structure. The structure is constructed from transversal beams, what are exploited as natural reflectors. Figure 4 visualizes the estimated signal to ratio (SNR) of the signal's reflection, depending on the structure's range. The SNR is presented in linear units. A signal with a higher SNR above the threshold (green line) has a better quality, and there is an assumption of a higher degree of accuracy in determining the displacements.

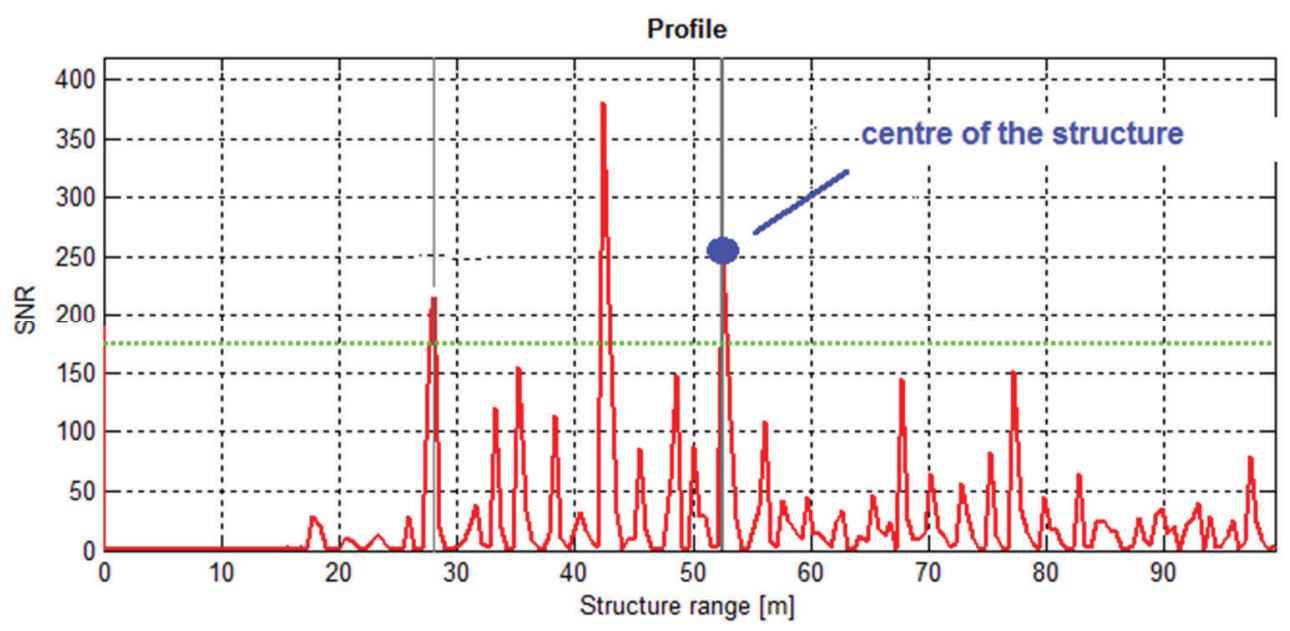

Figure 4: Range bin profiles

Table 1 shows the projected vertical displacements (way of projection is described by Figure 1 right) of the structure at the centre of the bridge. It can be seen, that time series of the displacements measured by accelerometers have a similar behaviour to displacements measured by radar.

The effect of pedestrians walking has a minimum influence on the vertical displacements. The rapid movement of pedestrians affects the maximum vertical displacements two times more than during the loading by a pedestrian's walking. The jumping of pedestrian affects the displacements up to $4.85 \mathrm{~mm}$ at the centre of the structure.
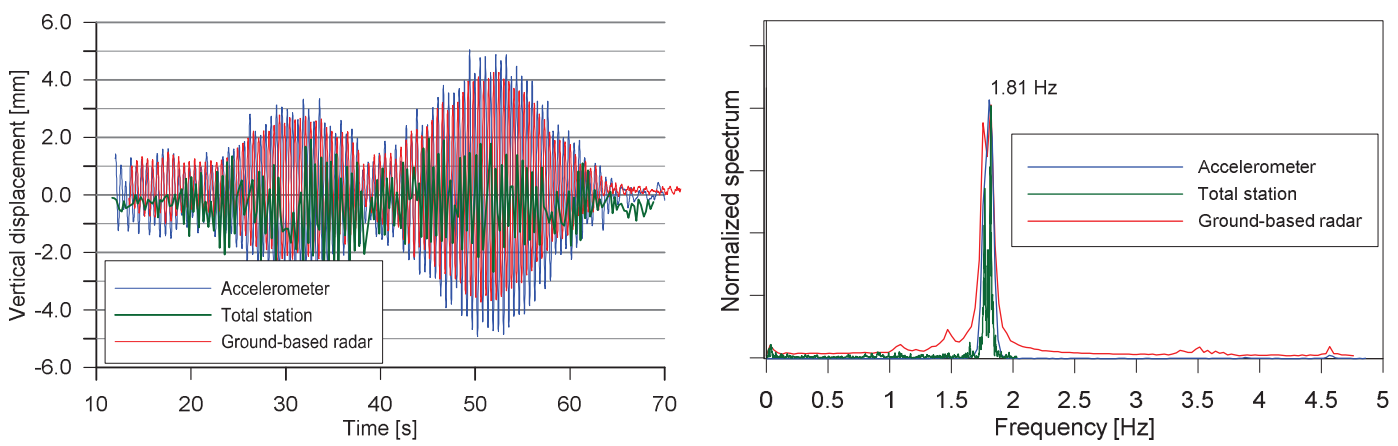

Figure 5: Displacements (left) and periodogram (right) during jumping-centre of the structure 
Table 1 Maximum displacements at the centre of the structure (in millimetres)

\begin{tabular}{|c|c|c|c|c|}
\hline Sensor & No load & Walking & Running & Jumping \\
\hline Accelerometer & 0.69 & 0.73 & 0.72 & 4.82 \\
\hline Ground-based radar & 0.71 & 0.74 & 0.76 & 4.63 \\
\hline Total station & 0.71 & 1.03 & 0.73 & 2.85 \\
\hline
\end{tabular}

Determining the natural frequencies of the structural deformations at the centre of the bridge was realized by an auto-spectral analysis using the Fast Fourier transformation (FFT) algorithm. Table 2 shows dominant frequencies of the deformations at the centre of the structure determined by each used type of sensors during different types of loading.

Table 2: Dominant frequencies of the deformations at the centre of the structure

\begin{tabular}{|c|c|c|c|c|c|}
\hline \multirow{2}{*}{$\begin{array}{l}\text { Vibration } \\
\text { mode }\end{array}$} & \multirow{2}{*}{$\begin{array}{c}\text { Natural } \\
\text { frequency } \\
{[\mathrm{Hz}]}\end{array}$} & \multicolumn{4}{|c|}{ Measurement } \\
\hline & & No load & Walking & Running & Jumping \\
\hline 2 & 1.63 & $\begin{array}{l}1.53^{(2)} \\
1.46^{(3)}\end{array}$ & - & $\begin{array}{l}1.53^{(2)} \\
1.75^{(3)}\end{array}$ & - \\
\hline 22 & 2.15 & - & $\begin{array}{l}2.05^{(1)} \\
2.01^{(2)}\end{array}$ & - & $\begin{array}{l}1.80^{(1)} \\
1.82^{(2)} \\
1.87^{(3)}\end{array}$ \\
\hline 23 & 2.49 & - & - & $\begin{array}{l}2.90^{(1)} \\
2.97^{(2)}\end{array}$ & - \\
\hline 44 & 3.76 & - & $\begin{array}{l}3.99^{(1)} \\
3.71^{(2)} \\
\end{array}$ & - & $3.51^{(2)}$ \\
\hline 59 & 4.69 & - & - & $\begin{array}{l}4.59^{(1)} \\
4.56^{(2)} \\
\end{array}$ & - \\
\hline & $>5.00$ & - & - & $\begin{array}{l}9.10^{(1)} \\
9.11^{(2)}\end{array}$ & $9.07^{(2)}$ \\
\hline
\end{tabular}

The FEM model contains 5 vibration modes of deformation, which have a significant influence on the structure's dynamic deformation. Vibration modes are defined for specific for specific type of loading. Table 2 shows the significant influence of pedestrians on the dynamic response of the monitored structure. The dominant frequencies of the deformations have a good rate of compliance with the $22^{\text {nd }}$ vibration mode of the structure which has a dominant influence on the structure's stability. The estimated frequencies approximately at the levels $1.80 \mathrm{~Hz}$ and $2.10 \mathrm{~Hz}$ level are affected by the walking and jumping of pedestrian, because the frequency of a pedestrian's steps and jumping has similar values. This assumption of dominant influence of structure stability was confirmed during the experiment by the low stability of the pedestrian moving on the structure. The most dominant frequency estimated in the time series higher than 5 $\mathrm{Hz}$ was at the level of $9.10 \mathrm{~Hz}$. This frequencies have minimum amplitudes with low influence on stability of the structure. Differences can be affected by accuracy of FEM model and by fact that dampers on the rods are not included in the FEM model calculation. The accuracy of the estimated frequencies in each time series is under the level of $1 \%$.

\section{Conclusion}

The paper presents possibilities for an analysis of structural dynamic deformations measured by ground-based radar, accelerometer and total station. A practical application of the processing and 
analysis of these data was realized at the cycling bridge at Devínska Nová Ves. The results of the experimental measurements correspond with the FEM model of the main steel structure and can be used for the calibration of this model. The realized measurements show a good application of ground-based radar technology. It is a perspective non-contact technology, which is able to monitor entire structure's deformation synchronously with high frequency. The accuracy of measured deformation is depended on system configuration and quality of reflected signal. This can be improved by corner reflectors, especially when the structure surface is low reflective. The results can significantly contribute to the prediction of possible failures of the structure, which can be reflected by anticipated temporal changes in the modal frequencies at the measured points of the structure. These failures can be investigated by other surveying methods such as terrestrial laser scanning.

\section{Acknowledgement}

This work was supported by the Slovak Research and Development Agency under the contract No. APVV-0236-12

\section{References}

[1] AGOCS, Z. - VANKO, M. (2011): Devínska Nová Ves - Schlosshof cycling-bridge. Project design - report. Bratislava : INGsteel, a.s., 25 pp. 2011, (in Slovak).

[2] BERNARDINI, G. - PASQUALE DE, G. - BICCI, A. - MARRA, M. - COPPI, F. RICCI, P. (2007): Microwave interferometer for ambient vibration measurements on civil engineering structures: 1 . Principles of the radar technique and laboratory tests. EVACES '07, 2007.

[3] EXCON, LTD. (2010): Evaluation of the dynamic FEM model of the Devínska Nová Ves - Schlosshof cycling-bridge. 42 pp. (in Slovak).

[4] GENTILE C. (2009): Radar-based measurement of deflections on bridges and large structures: advantages, limitations and possible applications. IV ECCOMAS thematic conference on Smart Structures and Materials (SMART'09), 2009, pp. 1-20.

[5] KOPÁČIK, A. - LIPTÁK, I. - KYRINOVIČ, P. - ERDÉLYI, J. (2013): Monitoring of a cycling bridge using accelerometers and ground-based radar - a case study. In 2nd Joint International Symposium on Deformation Monitoring : Nottingham, 9.-11.9.2013. Nottingham : University of Nottingham, 2013. 8 p.

[6] WENZEL, H. (2009): Health Monitoring of Bridges. John Wiley \& Sons, Ltd. 2009. 643 pp. ISBN 978-0-470-03173-5. 